\title{
Modified procedure for improved synthesis of some octameric silsesquioxanes via hydrolytic polycondenzation in the presence of Amberlite ion-exchange resins
}

\author{
Enock O. Dare, ${ }^{* a, b}$ Ling-Kang Liu ${ }^{b, c}$ and James Peng ${ }^{b}$ \\ Received 6th March 2006, Accepted 23rd May 2006 \\ First published as an Advance Article on the web 12th June 2006 \\ DOI: $10.1039 /$ b603325c
}

Practical alternative procedures are described for the syntheses of octavinylsilsesquioxane 1, octaphenylsilesquioxane and octabenzylsilsesquioxane. The hydrolytic polycondensation of $\mathrm{RSiX}_{3}$ $\left(\mathrm{R}=\mathrm{CH}_{2}=\mathrm{CH}-, \mathrm{C}_{6} \mathrm{H}_{5}-\right.$ or $\mathrm{C}_{6} \mathrm{H}_{5} \mathrm{CH}_{2}-; \mathrm{X}=\mathrm{Cl}, \mathrm{OCH}_{3}$, or $\left.\mathrm{OC}_{2} \mathrm{H}_{5}\right)$ in the presence of solid acid or base Amberlite ion-exchange resin gave improved yields of the corresponding octameric oligosilsesquioxanes. Repetitive usage of the Amberlite resin as the hydrolysis reagent was tested during synthesis of $\mathbf{1}$. The results indicate that it could be used many times in the same solvent making the procedure a more economically viable technique.

\section{Introduction}

Polyhedral oligosilsesquioxanes (POSS) (i.e., $\left[\mathrm{RSiO}_{1.5}\right]_{n}$ ) are an interesting class of three-dimensional spherosiloxanes derived from hydrolytic polycondensation of trifunctional organosilicon monomers (i.e., $\mathrm{RSiX}_{3}, \mathrm{X}=\mathrm{Cl}$, OMe or OEt). ${ }^{1}$ The name "spherosiloxanes" is sometimes used to describe these compounds, ${ }^{2}$ since they have polyhedral structures that are topologically equivalent to a sphere. Much attention has been paid to the investigation of these clusters as nanoscopic organicinorganic hybrids which are amorphous, crystalline or exhibit bicontinuous, columnar or lamella morphologies. ${ }^{3-5}$ Most of the practical and industrial interest in POSS is focused on octavinylsilsesquioxanes, which have attracted interest as dielectric films for integrated circuits, ${ }^{6}$ and also as resist for the electron lithographic manufacture of semiconductor microreliefs. ${ }^{1}$ Moreover, there has also been interest in phenylsilsesquioxane, which exhibits remarkable thermal stability and have found application as binders for ceramics, ${ }^{7}$ and liquid crystal display elements. ${ }^{8}$ Recently, hydridosilsesquioxanes have been focused to serve as photoresist ${ }^{9}$ and precursors to spherosilicates. ${ }^{10}$ Despite the great industrial utilities of the aforementioned octameric clusters, their chemistry still remained underdeveloped due to a lack of efficient and high yielding synthetic procedures. A large percentage of reported procedures for octasilsesquioxanes utilized mineral acid, which was either part of the reacting species or generated from the reacting trichlorosilanes for hydrolysis. Agaskar's procedure ${ }^{11}$ utilized large amount of Brønsted acid $\mathrm{HCl}(\mathrm{aq})$ and Lewis acid $\mathrm{FeCl}_{3}$ (aq) to synthesize hydridosilsesquioxanes, and the results suggested that further modifications of the procedure may lead to efficient and convenient synthesis of other POSS. Therefore, we report a modified procedure wherein both Brønsted acid

${ }^{a}$ Department of Chemistry, University of Agriculture, P. O. Box 28, UNAAB Post Office, Abeokuta, Nigeria.E-mail: dare3160@hotmail.com

${ }^{b}$ Institute of Chemistry, Academia Sinica, Nankang, Taipei, Taiwan 11529, Taiwan, $R O C$

'Department of Chemistry, National Taiwan University, Taipei, Taiwan 10767, Taiwan, ROC
$\mathrm{HCl}$ (aq) and Lewis acid $\mathrm{FeCl}_{3}$ (aq) were replaced with solid acid or base (Amberlite ion-exchange resin) in the hydrolysis of organomonosilanes to produce some octasilsesquioxanes in a relatively shorter reaction time with significantly higher yields.

\section{Results and discussion}

A pioneering report of the synthesis of $\mathbf{1}$ in 1958 by Olsson ${ }^{12}$ did not include adequate experimental and analytical information. Reinvestigation into the synthetic procedure in 1978 by Andrianov and associates ${ }^{13}$ using hydrolytic polycondensation of vinyltrichlorosilane yielded $6 \%$ of $\mathbf{1}$. Voronkov et al. ${ }^{14}$ also synthesized 1 with $10 \% \mathrm{HCl}$ for hydrolysis. The recent effort ${ }^{15}$ utilized vinyltriethoxysilane as substrate and took several days reaction time to produce a few percent of $\mathbf{1}$.

Our recently attempted work on the synthesis of hydridosilsesquioxane ${ }^{16}$ using Amberlite cation exchange resin $\left(\mathrm{RSO}_{3}{ }^{-} \mathrm{H}^{+}\right.$, medium porosity IR-120 PLUS) induced us to examine the solid acid or solid base in the hydrolytic polycondensation of some organosilanes, $\mathrm{RSiX}_{3}(\mathrm{R}=$ vinyl, phenyl or benzyl; $\mathrm{X}=\mathrm{Cl}$, $\mathrm{OMe}$, or OEt). Compound $\mathbf{1}$ was synthesized by the hydrolytic condensation of $\mathrm{RSiX}_{3}$ in an excess of methanol containing acid Amberlite for hydrolysis. The synthetic procedure adopted, as compared with the literature methods, is shown in Scheme 1.

Within $13 \mathrm{~h}$ of reaction in the presence of vinyltrichlorosilane, there was spontaneous precipitation of $\mathbf{1}$ from the reaction mixture to give a yield of $23.90 \%$ in the first cycle. Repetitive usage of the solid acid was tested by recycling the reactions with the same Amberlite and methanol after regeneration with $\mathrm{HCl}$ and then washed with methanol.

From the graphical plot of the yield against daily entries using vinyltrichlorosilane as substrate (Fig. 1), a maximum yield (41\%) was reached at the third cycle, which was almost constant between cycles 2 and 4 in an Amberlite regenerated condition. However, there was a gross exponential decrease in the conversion under unregenerated conditions. The results indicate that Amberlite could be used many times in the same methanolic solution making the procedure a more economically viable system. In addition 


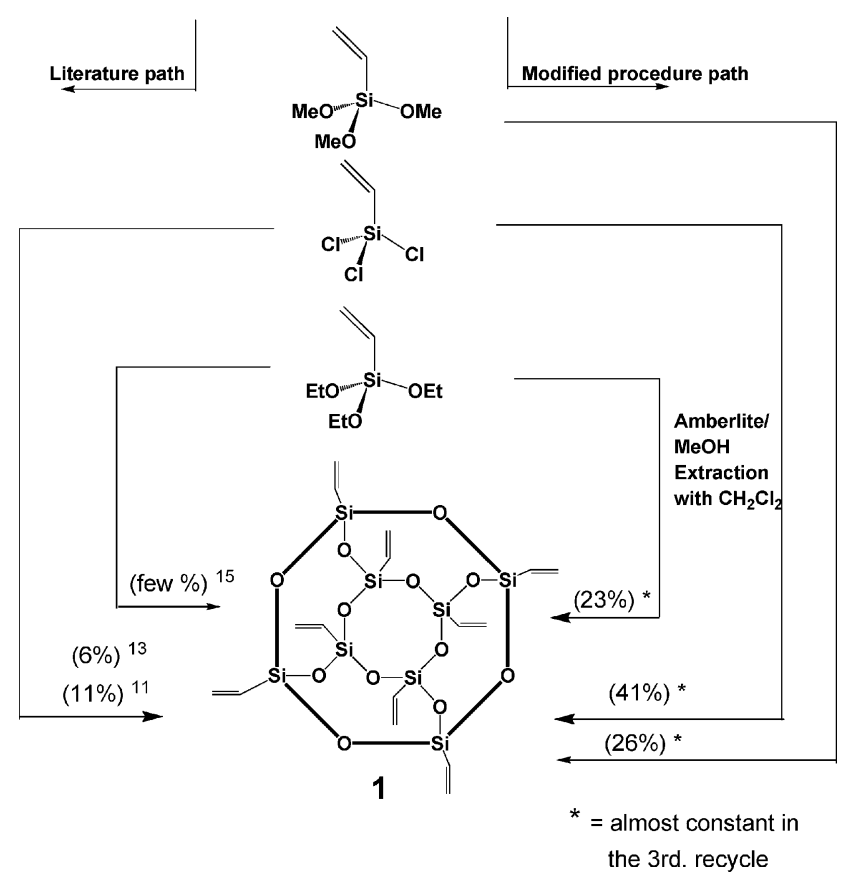

Scheme 1 Comparative synthetic procedures for octavinylsilsesquioxane 1.

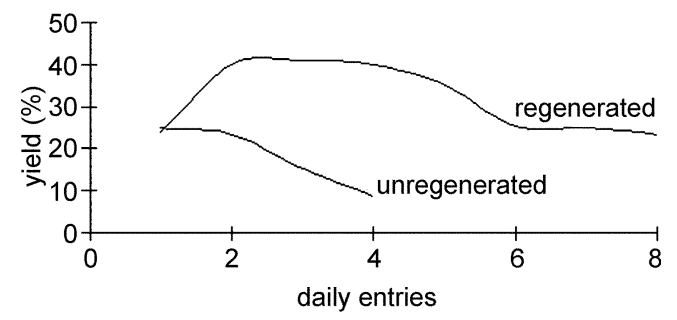

Fig. 1 Plots of yield against daily entries in regenerated and unregenerated conditions using vinyltrichlorosilane as substrate.

to the deposited microcrystals of $\mathbf{1}$ in the fifth cycle, derived gel (xerogel) was also obtained, thus lowering conversion from 40 to $35.12 \%$. The xerogel formation continues to the eighth cycle (Table 1). The derived xerogel was reported ${ }^{18}$ to find application as major ceramic precursor. Bonhomme et al. also reported ${ }^{15}$ acidic hydrolysis of triethoxyvinylsilane, which led to 1 (small $\%$ yield) and derived gel. Therefore, it could be noted in this report that the formation of microcrystals of $\mathbf{1}$ from a media, which led to a xerogel, may also be of interest for the selective preparation of ceramic ingredients. The gel formation is an indication that in these cycles, the rate of hydrolysis is greater than condensation. In the fifth cycle, while recycling the same methanolic solution, the acidity of the media was substantially higher since vinyltrichlorosilane continuously releases $\mathrm{HCl}$ on its own upon hydrolysis. The result provides a basis for $\mathrm{pH}$ control and which eventually determine the types of vinysilsesquioxanes formed. ${ }^{17}$

Under the same experimental conditions, the reaction was conducted with $\mathrm{H}_{2} \mathrm{C}=\mathrm{CHSi}\left(\mathrm{OCH}_{3}\right)_{3}$ or $\mathrm{H}_{2} \mathrm{C}=\mathrm{CHSi}\left(\mathrm{OC}_{2} \mathrm{H}_{5}\right)_{3}$ replacing $\mathrm{H}_{2} \mathrm{C}=\mathrm{CHSiCl}_{3}$ as substrate. At the third cycle, the yield of $\mathbf{1}$ was 26 and $23 \%$ (Table 1) using vinyltrimethoxysilane and vinyltriethoxysilane, respectively. In both cases, no gelation occurs, despite decreases in yields thereafter. The steric effects of the
Table 1 Representation of vinyl- $\mathrm{T}_{8}$ yield under regenerated/ unregenerated conditions with vinyltrichlorosilane or vinytriethoxysilane as substrate

\begin{tabular}{lllll}
\hline Cycle no. & Days & Volume $^{a} / \mathrm{mL}$ & Yield $^{b}(\%)$ & Yield $^{c}(\%)$ \\
\hline 1 & First & 4.0 & $23.90^{d} / 12.10^{e} / 12.69^{f}$ & 24.88 \\
2 & Second & 4.0 & $40.00^{d} / 21.11^{e} / 20.49^{f}$ & 23.41 \\
3 & Third & 4.0 & $41.00^{d} / 26.12^{e} / 22.93^{f}$ & 15.12 \\
4 & Fourth & 4.0 & $40.00^{d} / 25.0^{e} / 20.49^{f}$ & 8.77 \\
5 & Fifth & 4.0 & $35.12^{d} / 26.0^{e} / 12.20^{f}$ & 1.23 \\
6 & Sixth & 4.0 & $25.36^{d} / 18.22^{e} / 11.22^{f}$ & $\mathrm{nd}^{g}$ \\
7 & Seventh & 4.0 & $24.87^{d} / 14.35^{e} / 10.73^{f}$ & nd \\
8 & Eighth & 4.0 & $23.41^{d} / 14.0^{e} / 9.78^{f}$ & nd
\end{tabular}

${ }^{a}$ The volumes are the same for all substrates. ${ }^{b}$ Regenerated condition. ${ }^{c}$ Unregenerated condition with vinyltrichlorosilane. ${ }^{d}$ Percentage yield from vinytrichlorosilane. ${ }^{e}$ Percentage yield from vinyltrimethoxysilane. ${ }^{f}$ Percentage yield from vinyltriethoxysilane. Volume of the reaction solvent (methanol) remains constant at $150 \mathrm{~mL}$ for all experiments. ${ }^{g}$ Not determined (nd).

R-group on the monoorganosilanes determine, to a significant extent, the level of hydrolysis and condensation. As expected, the hydrolysis trend increases in the order $\mathrm{C}_{2} \mathrm{H}_{5} \mathrm{O}<\mathrm{CH}_{3} \mathrm{O}<\mathrm{Cl}$. Sprung and Guenther ${ }^{19}$ observed the same pattern while studying the hydrolytic polycondensation of some monosilanes.

Efforts were made to prepare octaallylsilsesquioxane from allyltrichlorosilane using acid or base Amberlite and following the same experimental procedure. The yield obtained fell below expectation as only a few percent of allyl- $\mathrm{T}_{8}\left(\mathrm{~T}_{8}=\left[\mathrm{Si}_{8} \mathrm{O}_{12}\right]^{-8}\right)$ was obtained. Therefore, it was not possible to improve on the yield $(7 \%)$ reported earlier. ${ }^{20}$

Octaphenylsilsesquioxane (phenyl- $\mathrm{T}_{8}$ ) has been synthesized in high yield (74\%) using a solid base Amberlite (IR 400). The reaction failed in the presence of an acid Amberlite. It was synthesized according to eqn (1).

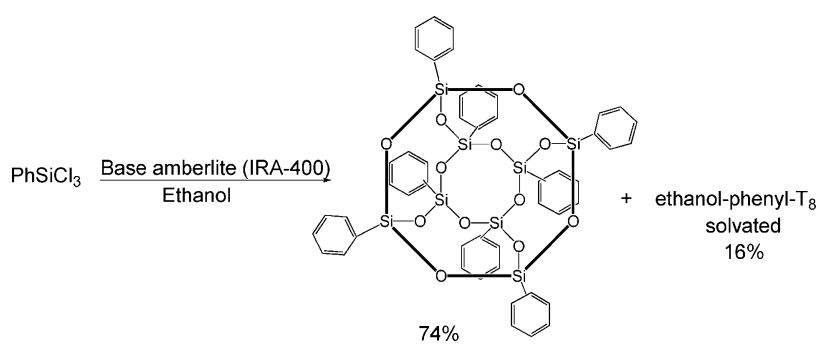

Reports $^{21-23}$ of this reaction indicated that organosilanes undergo hydrolysis by both acid and base-catalyzed mechanisms. The report ${ }^{23}$ stated that when an alkaline solution of phenyltrichlorosilane was allowed to stand at $30^{\circ} \mathrm{C}$, precipitation of some solvated solid phase was observed. With different solvents, the products could be phenyl- $\mathrm{T}_{8}$ or phenyl- $\mathrm{T}_{12}$. Therefore, we carried out hydrolysis of phenyltrichlorosilane with base Amberlite. The reaction conducted in ethanol gave phenyl- $T_{8}$ quantitatively (eqn (1)). It is noteworthy that ethanol does not only serve as reaction solvent, but also stabilized the formation of a large percentage of completely condensed octaphenylsilsesquioxane. The remaining $\mathrm{CH}_{2} \mathrm{Cl}_{2}$-soluble product isolated $(16 \%)$ is presumed to be phenyl- $\mathrm{T}_{8}$ solvated with ethanol. The peak at $1079\left(18 \%, \mathrm{M}^{+}\right)$and other fragmented pattern revealed the presence of an ethanol-solvated product. Phenyl- $\mathrm{T}_{8}$ solvated with acetone was reported previously. ${ }^{23}$ 


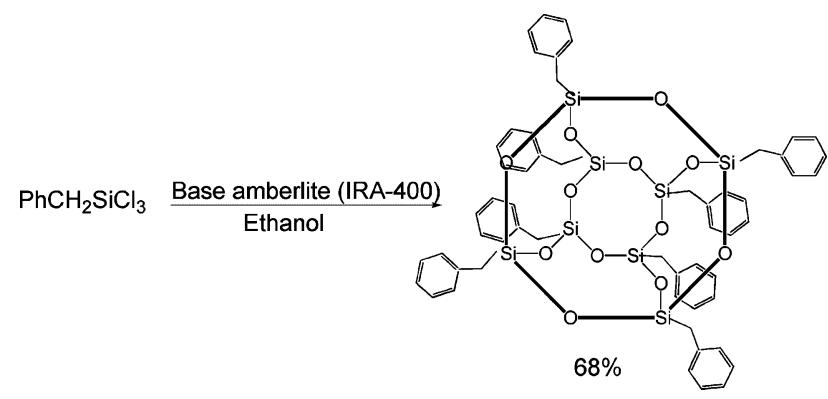

Following reaction (2), octabenzylsilsesquioxane was synthesized in ethanol using the solid base Amberlite for hydrolysis. The quantitative product of benzyl- $\mathrm{T}_{8}(68 \%)$ was obtained after trituration of the resinous semi-liquid.

For all the products in this report, analytical data obtained using various spectroscopic techniques and elemental analysis conforms with the literature data. ${ }^{13-17}$ IR spectrometric data of the xerogel is close to that of $\mathbf{1}$.

The preparation and regeneration process of the Amberlite ionexchange resin for acid- and base-type are indicated in eqn (3) and (4) respectively.
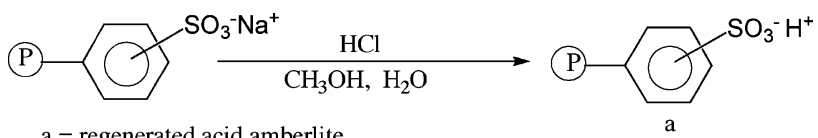

$\mathrm{a}=$ regenerated acid amberlite
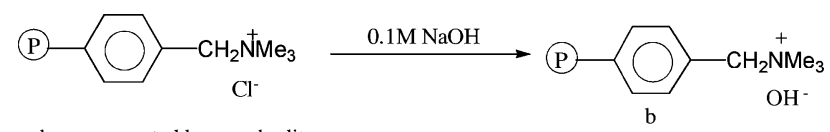

(4)

$\mathrm{b}=$ regenerated base amberlite

They are chemically modified gel-type polystyrene beads, which have been stored in $\mathrm{Na}^{+}$form (acid Amberlite) and $\mathrm{Cl}^{-}$form (base Amberlite). When required, presumably the $\mathrm{Na}^{+}$form of the acid resin, and $\mathrm{Cl}^{-}$form of the basic resin are converted to the active $\mathrm{H}^{+}$and $\mathrm{OH}^{-}$versions respectively by treatment with homogeneous acid and base. Consequently, hydrolysis/condensation of the $\mathrm{RSiX}_{3}$ took place giving completely condensed octavinylsilsesquioxane.

The chemistry of the synthesis of $\mathbf{1}$ has been established in the literature. ${ }^{13-15}$ A sol-gel process, which involves hydrolytic condensation of organotrichloro- (or methoxy- or ethoxy-) silane remain the main route of synthesis (Scheme 2).

The chloro or alkoxide groups on the silicon atoms are hydrolyzed to silanols and subsequently condensed with each other to give rise to siloxane bonds through a series of transformations.

\section{Conclusion}

An alternative method has been developed for the synthesis of some known polyhedral oligomeric silsesquioxanes. The sol-gel procedure, which utilized ion-exchange solid acid or base Amberlite for hydrolysis gave improved yields of octavinylsilsesquioxane, octaphenylsilsesquioxane and octabenzylsilsesquioxane in a much shorter time. Therefore, literature pathways, which requires high inorganic acid concentration, long reaction times and tedious extraction processes have been avoided, which makes the procedure an economically advantageous process by virtue of the possible repetitive usage of the Amberlite and solvent. The requisite improved yields in the case of octaallylsilsesquioxane and hydridosilsesquioxane ${ }^{5}$ leaves much to be desired as it was not possible to improve on the $7 \%{ }^{20}$ and $17.5 \%{ }^{11}$, respectively, reported in the literature. These results strongly suggest that further modification of this procedure may create possibilities for the future synthesis of other POSS.

\section{Experimental}

\section{General}

All reactions were carried out in an inert atmosphere unless otherwise noted. Reagents used were obtained from commercial sources (e.g., Aldrich and Fluka Chemicals Co.) and were used without further purification. Benzyltrichlorosilane was prepared according to a literature procedure. ${ }^{24}$ IR spectra were recorded in $\mathrm{CH}_{2} \mathrm{Cl}_{2}$ unless otherwise stated, using a $\mathrm{CaF}_{2}$ optic on a PerkinElmer 882 spectrophotometer. The ${ }^{1} \mathrm{H}$ NMR, ${ }^{13} \mathrm{C} \mathrm{NMR}$ and ${ }^{29} \mathrm{Si}$ NMR were obtained on a Bruker AC 300 spectrometer. Chemical shifts are reported in $\delta$ values relative to the residual solvent resonance of $\mathrm{CDCl}_{3}\left({ }^{1} \mathrm{H}, \delta 7.24 ;{ }^{13} \mathrm{C}, \delta 77.0\right), \mathrm{C}_{6} \mathrm{D}_{6}\left({ }^{1} \mathrm{H}, \delta 7.15\right)$. Low-resolution mass spectra were recorded on a VG 70-250s mass

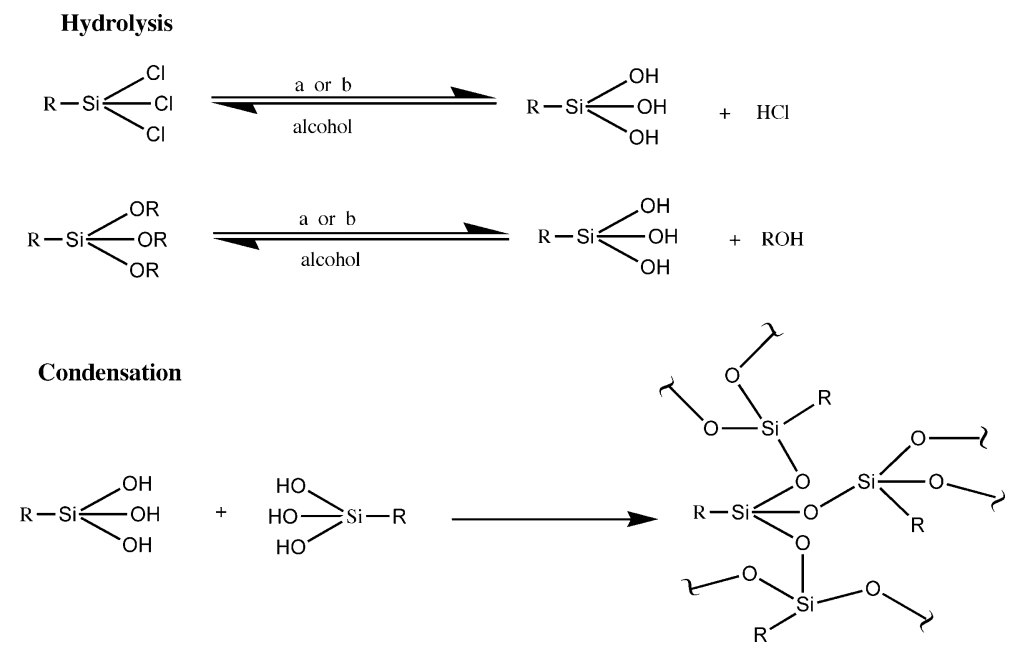

Scheme 2 Hydrolytic polycondensation of $\mathrm{RSiX}_{3}$ in the presence of Amberlite ion-exchange resins a or $\mathrm{b}$. 
spectrometer using the FAB technique. Microanalytical data were obtained with the use of a Perkin-Elmer 240C elemental analyzer.

Acid Amberlite $\left(\mathrm{RSO}_{3}{ }^{-} \mathrm{H}^{+}\right.$, IR-120 PLUS) was regenerated after use by washing with concentrated hydrochloric acid, water and methanol, while basic Amberlite (IRA-400) was regenerated after use by washing with $0.1 \mathrm{M} \mathrm{NaOH}$ solution.

\section{Synthesis of octavinylsilsesquioxane $\left(\mathrm{H}_{2} \mathrm{C}=\mathrm{CH}\right)_{8} \mathrm{Si}_{8} \mathrm{O}_{12} 1$}

Acid Amberlite of medium porosity (40 g) was washed with concentrated hydrochloric acid, water and methanol before charging it into a $500 \mathrm{~mL}$ flask, which was equipped with a magnetic stirrer. Methanol $(150 \mathrm{~mL})$ was added and stirred at $30{ }^{\circ} \mathrm{C}$. Vinyltrichlorosilane $(4.0 \mathrm{~mL}, 0.04 \mathrm{~mol})$ was added slowly with stirring to the Amberlite methanolic solution. The stirring continued at room temperature for $10 \mathrm{~h}$ during which white microcrystals were deposited on the wall of the flask. Methanol was decanted into a pre-prepared $500 \mathrm{~mL}$ flask (to be reused in the next experiment). Dichloromethane was added to dissolve the microcrystals and the Amberlite was filtered out for reuse in subsequent experiments. The solvent was evaporated and the vinyl- $\mathrm{T}_{8}$ microcrystals washed several times with methanol. The recycled Amberlite was used 8 times, and xerogel was isolated in addition to the microcrystals from the fifth experiment onward. ${ }^{1} \mathrm{H} \mathrm{NMR}\left(\mathrm{CDCl}_{3}\right): \delta$ 5.69-6.15 ppm $\left(\mathrm{m}, \mathrm{H}_{2} \mathrm{C}=\mathrm{CH}-, 24 \mathrm{H}\right) ;{ }^{13} \mathrm{C}$ $\mathrm{NMR}\left(\mathrm{CDCl}_{3}\right): \delta 128.70 \mathrm{ppm}(\mathrm{C} 1), 136.95 \mathrm{ppm}(\mathrm{C} 2) ;{ }^{29} \mathrm{Si}-$ NMR $\left(\mathrm{CDCl}_{3}\right): \delta-79.8 \mathrm{ppm},-80.6 \mathrm{ppm}\left(-\mathrm{SiCH}=\mathrm{CH}_{2}\right)$; IR $\left(\mathrm{CaF}_{2}, \mathrm{~cm}^{-1}\right): 3067.8(\mathrm{C}-\mathrm{H}), 1604.6(\mathrm{C}=\mathrm{C}), 1408(\mathrm{C}-\mathrm{H}) 1118.1$ ( $\mathrm{Si}-\mathrm{O}-\mathrm{Si}) 784(\mathrm{Si}-\mathrm{C})$; MS (FAB) : $633.2\left(\mathrm{M}^{+}\right.$, parent ion). Elem. anal. Calcd for $\mathrm{C}_{16} \mathrm{H}_{24} \mathrm{Si}_{8} \mathrm{O}_{12}$ : C, 30.36; H, 3.79\%; Found: C, 30.31; $\mathrm{H}, 3.70 \%$.

IR data for Xerogel: IR $\left(\mathrm{CaF}_{2}, \mathrm{~cm}^{-1}\right): 3064.3,1603.6,1126$, 1410,785

The same procedure as described above was followed when vinylmethoxysilane or vinylethoxysilane was used as a substitute for vinyltrichlorosilane.

\section{Synthesis of octaphenylsilsesquioxane $\left(\mathrm{C}_{6} \mathrm{H}_{5}\right)_{8} \mathrm{Si}_{8} \mathrm{O}_{12}$}

Base Amberlite (IRA 400, $20 \mathrm{~g}$ ) was placed into a flask equipped with magnetic stirrer. Ethanol $(95 \%, 100 \mathrm{~mL})$ was added and stirred. While stirring, phenyltrichlorosilane (12.69 g, $0.06 \mathrm{~mol})$ was slowly added to the reaction mixture, and stirring was maintained overnight. The deposited white microcrystals were harvested and washed with small amount of dichloromethane to give white microcrystals. Yield $5.74 \mathrm{~g}(74 \%)$.

${ }^{1} \mathrm{H}$ NMR $\left(\mathrm{C}_{6} \mathrm{D}_{6}\right): \delta 7.33 \mathrm{ppm}\left(\mathrm{t}, \mathrm{C}_{6} \mathrm{H}_{5}\right), 7.72 \mathrm{ppm}\left(\mathrm{m}, \mathrm{C}_{6} \mathrm{H}_{5}\right) ;{ }^{13} \mathrm{C}$ $\operatorname{NMR}\left(\mathrm{C}_{6} \mathrm{D}_{6}\right): \delta 127.74,130.66,133.66,134.08 \mathrm{ppm} ; \mathrm{IR}\left(\mathrm{C}_{6} \mathrm{H}_{6}\right.$, $\left.\mathrm{CaF}_{2}, \mathrm{~cm}^{-1}\right): 3083.0(\mathrm{C}-\mathrm{H}), 2924.5(\mathrm{C}-\mathrm{H}), 1610(\mathrm{C}=\mathrm{C}), 1588.7$ $(\mathrm{C}=\mathrm{C}), 1141.5$ ( $\mathrm{Si}-\mathrm{O}-\mathrm{Si})$; MS (FAB): $1033.0\left(\mathrm{M}^{+}\right.$, parent ion). Elem. anal. Calcd for $\mathrm{C}_{48} \mathrm{H}_{40} \mathrm{Si}_{8} \mathrm{O}_{12}: \mathrm{C}, 55.80 ; \mathrm{H}, 3.87 \%$; Found: $\mathrm{C}$, 55.23 ; H, 3.34\%.

\section{Synthesis of octabenzylsilsesquioxane $\left(\mathrm{C}_{6} \mathrm{H}_{5} \mathrm{CH}_{2}\right)_{8} \mathrm{Si}_{8} \mathrm{O}_{12}$}

Base Amberlite (IRA 400, $30 \mathrm{~g}$ ) was placed into a flask equipped with magnetic stirrer. Ethanol $(95 \%, 100 \mathrm{~mL})$ was added and stirred. While stirring, benzyltrichlorosilane (10 g, $0.044 \mathrm{~mol})$ was slowly added to the reaction mixture, stirring was maintained overnight and a cloudy white liquid was observed. $80 \%$ of the solvent was evaporated resulting in a white semi-liquid, which was triturated ${ }^{25}$ to give white powder yielding $4.33 \mathrm{~g}(68 \%)$.

${ }^{1} \mathrm{H}$ NMR $\left(\mathrm{CDCl}_{3}\right): \delta 7.33\left(\mathrm{t}, \mathrm{C}_{6} \mathrm{H}_{5}\right), 7.72 \mathrm{ppm}\left(\mathrm{m}, \mathrm{C}_{6} \mathrm{H}_{5}\right) ;{ }^{13} \mathrm{C}$ $\mathrm{NMR}\left(\mathrm{CDCl}_{3}\right): \delta 127.74,130.66,133.66,134.08 \mathrm{ppm} ;{ }^{29} \mathrm{Si} \mathrm{NMR}$ $\left(\mathrm{CDCl}_{3}\right): \delta-71.44 \mathrm{ppm}\left(-\mathrm{SiCH}_{2} \mathrm{Ph}\right)$; IR $\left(\mathrm{CHCl}_{3}, \mathrm{CaF}_{2}, \mathrm{~cm}^{-1}\right)$ : $3083.0(\mathrm{C}-\mathrm{H}), 2924.5(\mathrm{C}-\mathrm{H}), 1610(\mathrm{C}=\mathrm{C}), 1588.7(\mathrm{C}=\mathrm{C}), 1141.5$ (Si-O-Si); MS (FAB): $1033.0\left(\mathrm{M}^{+}\right.$, parent ion). Elem. anal. Calcd for $\mathrm{C}_{48} \mathrm{H}_{40} \mathrm{Si}_{8} \mathrm{O}_{12}$ : C, 55.80; H, 3.87\%; Found: C, 55.23; $\mathrm{H}$, $3.34 \%$.

\section{Acknowledgements}

The authors are thankful to the Institute of Chemistry, Academia Sinica and the National Research Council, Taiwan, ROC, for financial assistance granted toward this project.

\section{References}

1 M. G. Voronkov and V. I. Lavrent'yev, Top. Curr. Chem., 1982, 102, 199.

2 D. A. Armitage, Inorganic Rings and Cages, Edward Arnold Ltd, London, 1972, p. 218.

3 R. Elsaber, G. H. Mehl, J. W. Goodby and D. J. Photinos, Chem. Commun., 2000, 851.

4 A. Sellinger, P. M. Weiss, A. Nguyen, Y. Lu, R. A. Assink, W. Gong and C. F. Brinker, Nature, 1998, 394, 256.

5 C. G. Goltner, Angew. Chem., Int. Ed., 1999, 38, 3155.

6 V. P. Korchkov, T. N. Martynova and V. I. Belyi, Thin Solid Films, 1983, 101, 373.

7 (a) T. Mine and S. Komasaki, Jpn. Pat., Kokai-s-60-210570, 1985; (b) T. Mine and S. Komasaki, Chem. Abstr., 1986, 104, 154450.

8 (a) F. Shoji, R. Sudo and T. Watanabe, Jpn. Pat., Kokai-s-56-146120, 1981; (b) F. Shoji, R. Sudo and T. Watanabe, Chem. Abstr., 1982, 96, 208471.

9 (a) H. Tosaka, K. Yamaguchi, M. Orihara, N. Ide and K. Otaki, Jpn. Pat., 24268, 1987; (b) H. Tosaka, K. Yamaguchi, M. Orihara, N. Ide and K. Otaki, Chem. Abstr., 1987, 107, 124570.

10 P. A. Agaskar, V. W. Day and W. G. Klemperer, J. Am. Chem. Soc., 1987, 109, 5554.

11 P. A. Agaskar, Inorg. Chem., 1991, 30, 2207.

12 K. Olsson, Ark. Kemi, 1958, 37, 367.

13 K. A. Andrianov, N. M. Petrovnina, T. V. Vasil'eva, V. E. Shklover and B. I. D'yachenko, Zh. Obshch. Khim., 1978, 48, 2692.

14 M. G. Voronkov, T. N. Martynova, R. G. Mirskov and V. I. Belyi, Zh. Obshch. Khim., 1979, 49, 1522.

15 C. Bonhomme, P. Toledano, J. Maquet, J. Livage and L. BonhommeCoury, J. Chem. Soc., Dalton Trans., 1997, 1617.

16 Ling-Kang Liu and E. O. Dare, J. Chin. Chem. Soc., 2004, 51, 175.

17 L. D. Field, C. M. Lindall, T. Maschmeyer and A. F. Masters, Aust. J. Chem., 1994, 47, 1127.

18 D. A. Loy and K. J. Shea, Chem. Rev., 1995, 95, 1431.

19 M. M. Sprung and F. O. Guenther, J. Am. Chem. Soc., 1955, 77, 3990.

20 T. N. Martynova, V. P. Korchkov and P. P. Semyannikov, J. Organomet. Chem., 1983, 258, 277.

21 B. Arkes, Chem.-Tech., 1977, 7, 766.

22 J. F. Brown, L. H. Vogt and P. I. Prescott, J. Am. Chem. Soc., 1964, 86, 1120.

23 K. Larson, Ark. Kem., 1960, 16, 209.

24 L. D. Rosenberg, J. J. Walburn and R. Ramsden, J. Org. Chem., 1957, 22, 1606.

25 F. J. Feher and T. A. Budzichowski, J. Organomet. Chem., 1989, 373, 153. 